\title{
A NOTE ON A PAPER BY S. HABER
}

\author{
A. MCD. MERCER \\ Department of Mathematics and Statistics \\ University of Guelph \\ Gue1ph, Ontario, Canada N1G 2W1
}

(Received September 23, 1982 and in revised form February 26, 1983)

ABSTRACT. A technique used by $\mathrm{S}$. Haber to prove an elementary inequality is applied here to obtain a more general inequality for convex sequences.

KEY WORDS AND PHRASES. Convex sequences, Hadamard's inequality for convex functions, rearrangements.

1980 MATHEMATICS SUBJECT CLASSIFICATION CODE. Primary 26015, Secondary 40605.

1. INTRODUCTION.

Let $a$ and $b$ be non-negative. Then the following elementary inequality was proved in [1].

$$
\frac{1}{n+1}\left[a^{n}+a^{n-1} b+. .+b^{n}\right] \geq\left(\frac{a+b}{2}\right)^{n} \quad(n=0,1,2, \ldots) \ldots
$$

Now this inequality can be obtained at once by taking $f(t)=t^{n}$ in the wellknown result

$$
\frac{1}{b-a} \int_{a}^{b} f(t) d t \geq f\left(\frac{a+b}{2}\right) \quad \ldots .
$$

which holds whenever $f$ is convex in $[a, b]$. However, the method used in [1] to obtain (1.1) is interesting and it is the purpose of the present note to show that it can be used to prove a considerably more general result about sequences. Indeed this more general result will have $(1.2)$ as a consequence.

2. MAIN RESULTS.

A lemma which we shall use is the following

LEMMA. If

$$
\beta_{0} \geq \beta_{1} \geq \beta_{2} \geq \ldots \geq \beta_{m}
$$

and

$$
\sum_{v=0}^{m} \alpha_{v}=0
$$


and if the ordering of the $\alpha_{v}$ is such that each positive $\alpha$ precedes all the negative ones, then

$$
\sum_{v=0}^{m} \alpha_{v} \beta_{v} \geq 0
$$

This lemma, which is easily proved, is not the one stated by Haber but, essentially, it is what he used. For with $b_{i}$ defined as in [1]

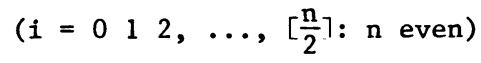

we do not in fact have

$$
\sum_{i=0}^{\left\lceil\frac{\mathrm{n}}{2}\right\rceil} b_{i}=0
$$

which is what is needed to apply the lemma quoted there.

Our result is the following.

THEOREM. Let $\left\{u_{v}\right\}_{v=0}^{n}$ be a convex sequence. Then

$$
\frac{1}{\mathrm{n}+1} \sum_{\nu=0}^{\mathrm{n}} \mathrm{u}_{\nu} \geq \frac{1}{2^{\mathrm{n}}} \sum_{\nu=0}^{\mathrm{n}}\left(\begin{array}{l}
\mathrm{n} \\
v
\end{array}\right) \mathrm{u}_{\nu} \cdots \cdots
$$

To see that (1.2) is a consequence of (2.1) let the function $f(x)$ be bounded and convex (and hence continuous) on $[a, b]$ and take

$$
u_{v}=f\left(a+\frac{v}{n}(b-a)\right)
$$

Then (2.1) reads

$$
\frac{1}{n+1} \sum_{n=0}^{n} f\left(a+\frac{\nu}{n}(b-a)\right) \geq \frac{1}{2^{n}} \sum_{\nu=0}^{n}\left({ }_{\nu}^{n}\right) f\left(a+\frac{\nu}{n}(b-a)\right) \ldots
$$

On letting $n \rightarrow \infty$ the left-hand side here tends to the left-hand side of (1.2). And by virtue of Bernstein's result

$$
\lim _{n \rightarrow \infty} \sum_{v=0}^{n}\left({ }_{v}^{n}\right) \phi\left(\frac{v}{n}\right)^{\nu}(1-x)^{n-v}=\phi(x) \ldots \cdots
$$

whenever $\phi \varepsilon \mathrm{C}[0,1]$ we see that the right-hand side of $(2.2)$ tends to $\mathrm{f}\left(\frac{\mathrm{a}+\mathrm{b}}{2}\right)$. Merely take $\phi(x)=f(a+x(b-a))$ and $x=1 / 2$ in (2.3).

We now proceed to prove (2.1).

PROOF. Following Haber let us put $Q=\left[\frac{\mathrm{n}}{2}\right]$ and write

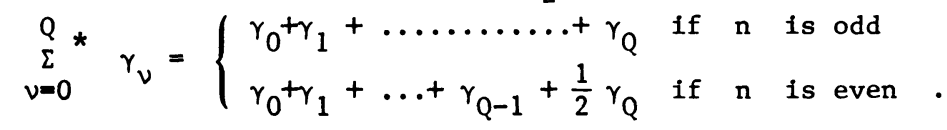

Then

$$
\frac{1}{n+1} \sum_{v=0}^{n} u_{v}-\frac{1}{2^{n}} \sum_{v=0}^{n}\left(\begin{array}{l}
n \\
)
\end{array}\right) u_{v}=\sum_{v=0}^{Q}{ }^{*} c_{v}\left[u_{v}+u_{n-v}\right]
$$


where

$$
c_{v}=\frac{1}{n+1}-\frac{1}{2^{n}}\left(\begin{array}{l}
n \\
v
\end{array}\right)
$$

Since $\left\{u_{v}\right\}_{v}^{n}=0$ is convex then

$$
u_{v+1}+u_{n-v-1} \leq u_{\nu}+u_{n-\nu} .(0 \leq v \leq Q-1)
$$

which is to say that the sequence $\left\{u_{v}+u_{n-v}\right\}_{v}^{Q}=0$ is non-increasing. We see too that the sequence $\left\{c_{\nu}\right\}_{\nu}^{Q}=0$ is non-increasing and that $\sum_{\nu=0}^{\beta *} c_{\nu}=0$. Appealing to the Lemma quoted above we find that

$$
\sum_{v=0}^{Q}{ }^{*} c_{\nu}\left[u_{v}+u_{n-v}\right] \geq 0
$$

and this complets the proof of (2.1).

In conclusion $I$ wish to thank the referee for his helpful advice concerning the lemma used here.

\section{REFERENCES}

1. HABER, S. An Elementary Inequality, Internat. J. Math. and Math. Sci. Vol. 2 No. 3 (1979) 531-535.

2. HARDY, G.H., LITTLEWOOD, J.E., POLYA, G., Inequalities Cambridge (1973). 


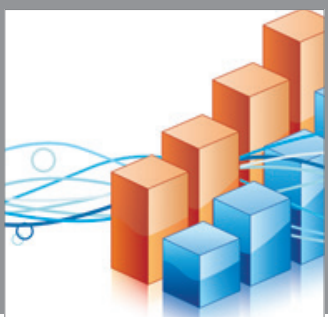

Advances in

Operations Research

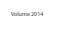

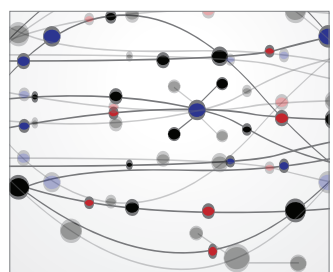

\section{The Scientific} World Journal
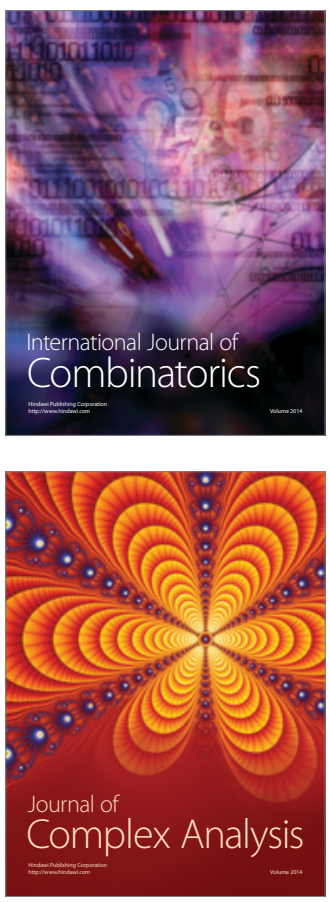

International Journal of

Mathematics and

Mathematical

Sciences
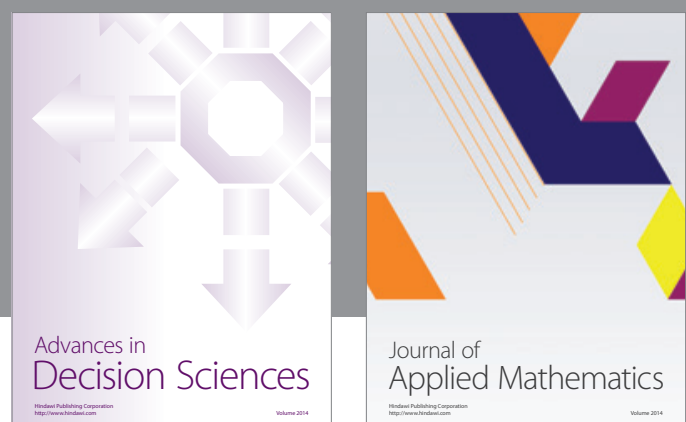

Journal of

Applied Mathematics
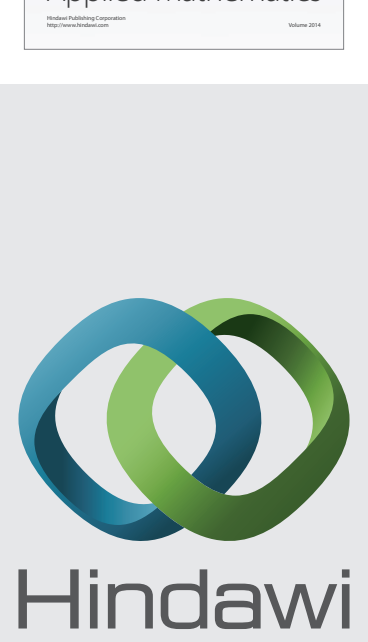

Submit your manuscripts at http://www.hindawi.com
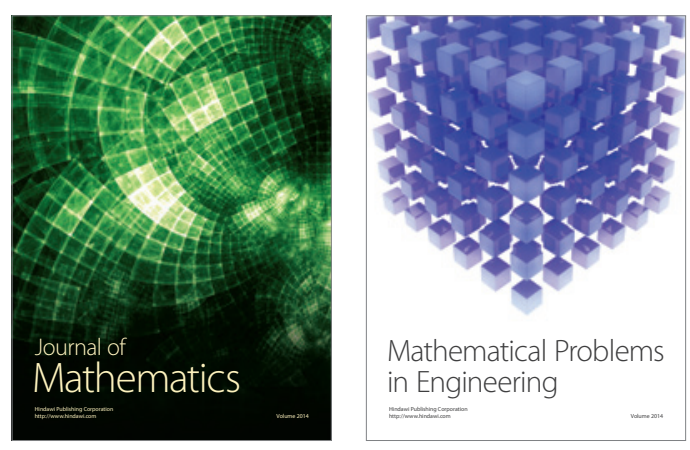

Mathematical Problems in Engineering
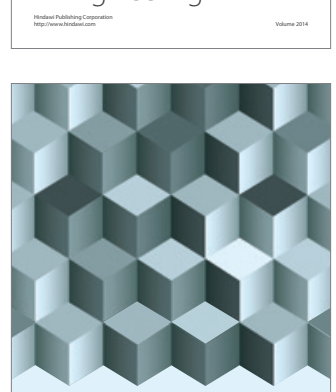

Journal of

Function Spaces
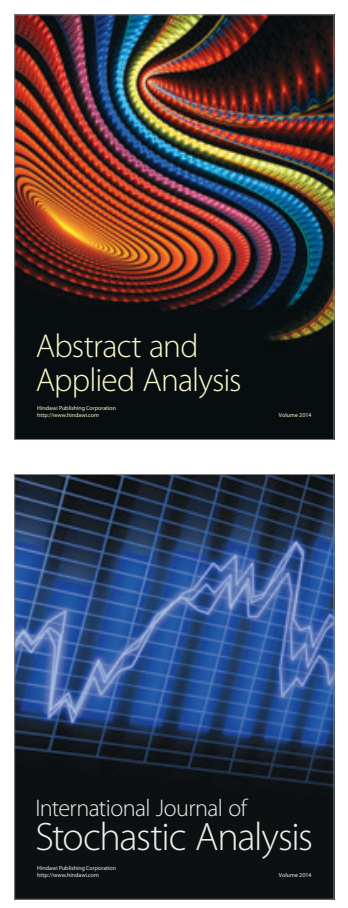

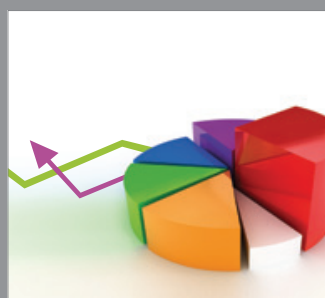

ournal of

Probability and Statistics

Promensencen
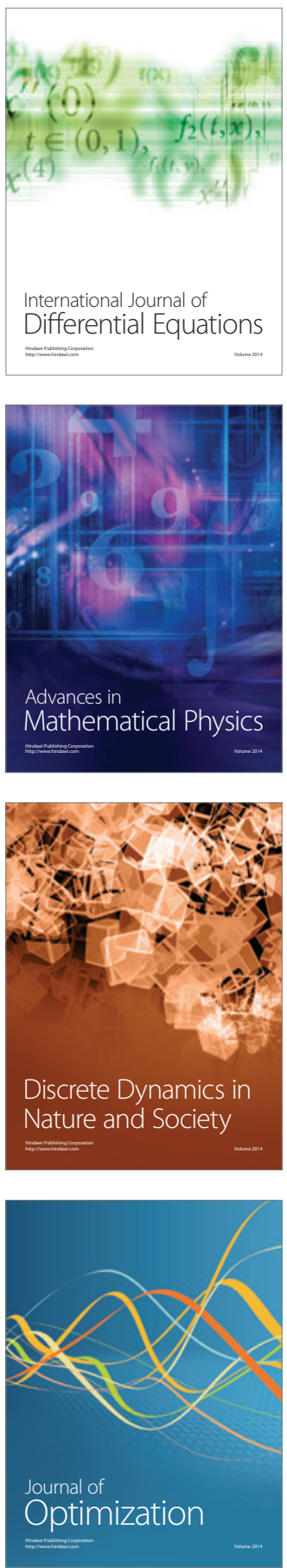